\title{
Early Post-operative Surveillance after Brain Surgery
}

\section{Bilotta Federico ${ }^{1,2 *}$, Guerra Carolina ${ }^{1}$ and Rosa Giovanni ${ }^{1}$}

${ }^{1}$ Department of Anaesthesiology, Critical Care and Pain Medicine, Sapienza University of Rome, Policlinico Umberto I, Rome, Italy

In the early postoperative phase after brain surgery, even after elective uncomplicated procedures, some clinical variables can affect brain perfusion and influence the outcome [1]. In these patients, safe discharge by the post anesthesia care unit is possible when physiologic variables return within normal values [2]. Nevertheless, to avoid postoperative complications it is mandatory a strict monitoring and thoughtful surveillance of qualified variables. Aim of this article is to highlight the clinical variables that qualify early postoperative phase after brain surgery and that -therefore- deserve close surveillance, including: hemodynamic, ventilation, neurologic and cognitive status, shivering, PONV, pain and metabolism.

\section{Hemodynamic}

The postoperative course of patients undergone brain surgery is often complicated by arterial hypertension due to sympathetic overdrive [3-5]. When cerebral auto-regulation is disturbed, arterial hypertension can results into direct increase of Cerebral Blood Flow (CBF) that can lead to high intracranial pressure, cerebral edema and intracranial hemorrhage $[1,3,5]$. In patients undergone elective craniotomy, thigh monitoring of arterial pressure and thoughtful titration of anti hypertensive drugs -including short acting beta blockers or calcium channel blockers- can effectively blunt the postoperative sympathetic overdrive [4,5]. Infusion of nitrates-based drugs, including nitroglycerin and nitroprusside, should be avoided in these patients, because of the direct cerebral vasodilatation and intracranial hypertension [5].

\section{Ventilation}

Reduced ventilation -with increase in $\mathrm{PaCO}_{2}$ values and reduction in $\mathrm{Ph}$ values- that some time complicates the postoperative course due to residual effects of anesthetic drugs, is especially dangerous after craniotomy because of the tight relationship between blood-gas analysis (BGA) values and $\mathrm{CBF}$ increases by $3 \%$ for each increase in $\mathrm{PaCO}_{2} \mathrm{mmHg}$ ) [6]. Surveillance of ventilatory function and BGA is therefore necessary to prevent complications related to $\mathrm{CBF}$ increase.

\section{Neurologic and Cognitive Status}

Neurologic and cognitive status at patients arrival in the duty should be immediately evaluated and recorded since the loss of a neurological and or cognitive ability might represent the initial sign of intracranial postoperative bleeding [2,7]. Surveillance of these functions should be performed on a pre defined time schedule and according a systematic approach. Subjective evaluation, when not supported by objective criteria (i.e. delay/inability to obey commands, lack of ability to move a limb, differences in pupils diameter, etc), can lead to a substantial underestimate.

\section{Shivering}

The appearance of postoperative shivering frequently complicates the postoperative course after brain surgery $[5,8]$. This complication is associated with a significant increase in blood oxygen extraction and in intracranial pressure; it therefore can lead to reduced brain perfusion. These patients deserve special attention to intra and postoperative normothermia that should be ensured, along with repeated/continuous core body temperature control, with active warming when needed.

\section{Postoperative Nausea and Vomiting (PONV)}

Occurrence of PONV after brain surgery is an especially serious complication since it might lead to aspiration and increase in intracranial pressure [9]. This complication should be prevented, by minimizing favoring factors, especially in high risk patients. These patients (female gender, patients with a previous episode of PONV, patients with infratentorial lesions, non smoking status, motion sickness disorder, etc) should be recognized right from hospital arrival and prophylactic regimen (use of short rather than long acting opioids, adequate fluid therapy, antiemetic medications, etc).

\section{Pain}

Occurrence of pain in the postoperative period after brain surgery is sometime overlooked [5,10-12]. Prevention of this serious complication is mostly associated with appropriate perioperative management, including the use of local anesthetics for scalp block in the intraoperative period, and adequate nociceptive therapeutic regimen. The use of NSAIDs after brain surgery is controversial because of the potential risks related to reduce platelet aggregation effects of these drugs and the potential to facilitate or worsen intracranial hemorrhage [10]. Opioids are effective, but should be used cautiously because of the possible effects on ventilator drive, consciousness and because can facilitate the occurrence of PONV.

\section{Metabolism}

Adequate nutrition and hydration is of paramount importance after intracranial surgery, because the brain only metabolizes glucose the blood glucose concentration (BGC) should kept within strict limits (not higher than $180 \mathrm{mg} / \mathrm{dl}$ not below $80 \mathrm{mg} / \mathrm{dl}$ ) [13-15]. In these patients the use of glucose enriched solution (5/10\% glucose solutions) should be avoided, because can provide free water that contribute to brain edema formation. In these patients fluid therapy should be limited to iso-osmolar solutions ( $0.9 \%$ saline) and nutrition guaranteed by using high protein enteral or parenteral solutions. Tight BGC monitoring with repeated whole blood BGC measurements should be performed [13-15].

In conclusion, some clinical variables -including hemodynamic, ventilation, neurologic and cognitive status, shivering and PONV, metabolism- are especially relevant after brain surgery and deserve to be strictly monitored. A qualified surveillance of these variables and a tight communication between health care professionals can significantly contribute to improve the post operative outcome of patients undergone brain surgery [16].

*Corresponding author: Federico Bilotta, Department of Anesthesiology, Critica Care and Pain Medicine, Sapienza University Rome, Italy, and Professor of Clinica Anesthesiology at the Albert Einstein College of Medicine, The Bronx, New York, NY, USA. E-mail: bilotta@tiscali.it

Received June 21, 2012; Accepted June 23, 2012; Published June 25, 2012

Citation: Federico B, Carolina G, Giovanni R (2012) Early Post-operative Surveillance after Brain Surgery. J Nurs Care 1:e112. doi:10.4172/2167-1168.1000e112

Copyright: ( 2012 Federico B, et al. This is an open-access article distributed under the terms of the Creative Commons Attribution License, which permits unrestricted use, distribution, and reproduction in any medium, provided the original author and source are credited. 


\section{References}

1. Basali A, Mascha EJ, Kalfas I, SchubertA(2000) Relation between perioperative hypertension and intracranial hemorrhage after craniotomy. Anesthesiology 93 : 48-54.

2. Aldrete JA, Kroulik D (1970) A postanesthetic recovery score. Anesth Analg 49: 924-934.

3. Bruder N, Pellissier D, Grillot P, Gouin F (2002) Cerebral hyperemia during recovery from general anesthesia in neurosurgical patients. Anesth Analg 94 650-654.

4. Bilotta F, Lam AM, Doronzio A, Cuzzone V, Delfini R, et al. (2008) Esmolol blunts postoperative hemodynamic changes after propofol-remifentanil total intravenous fast-track neuroanesthesia for intracranial surgery. J Clin Anesth 20: $426-430$.

5. Bruder NJ (2002) Awakening management after neurosurgery for intracranial tumours. Curr Opin Anaesthesiol 15: 477-482.

6. Bilotta F, Doronzio A, Cuzzone V, Caramia R, Rosa G, et al. (2009) Early postoperative cognitive recovery and gas exchange patterns after balanced anesthesia with sevoflurane or desflurane in overweight and obese patients undergoing craniotomy: a prospective randomized trial. J Neurosurg Anesthesiol 21: 207-213

7. Bilotta F, Caramia R, Paoloni FP, Favaro R, Araimo F, et al. (2007) Early postoperative cognitive recovery after remifentanil-propofol or sufentanilpropofol anaesthesia for supratentorial craniotomy: a randomized trial. Eur $J$ Anesthesiol 24: 122-127.
8. Bilotta F, Pietropaoli P, La Rosa I, Spinelli F, Rosa G (2001) Effects of shivering prevention on haemodynamic and metabolic demands in hypothermic postoperative neurosurgical patients. Anesthesia 56: 514-519.

9. Manninen PH, Tan TK (2002) Postoperative nausea and vomiting after craniotomy for tumor surgery: a comparison between awake craniotomy and general anesthesia. J Clin Anesth 14: 279-283.

10. Mordhorst C, Latz B, Kerz T, Wisser G, Schmidt A, et al. (2010) Prospective Assessment of postoperative pain after craniotomy. J Neurosurg Anesthesio 22: 202-206.

11. Hansen MS, Brennum J, Moltke FB, Dahl JB (2011) Pain treatment afte craniotomy: where is the (procedure specific) evidence? A qualitative systematic review. Eur J Anaesthesiol 28: 821-829.

12. Flexman AM, Ng JL, Gelb AW (2010) Acute and chronic pain following craniotomy. Curr Opin Anaesthesiol 23: 551-557.

13. Bilotta F, Giovannini F, Caramia R, Rosa G (2009) Glycemia management in neurocritical care patients. J Neurosurg Anesthesiol 21: 2-9.

14. Bilotta F, Rosa G (2010) Glucose management in the neurosurgical patient: are we yet any closer? Curr Opin Anaesthesiol 23: 539-543.

15. Bilotta F, Rosa G (2012) Glycemia management in critical care patients. World $\mathrm{J}$ Diabetes, in press.

16. Theofilou P (2011) Communication among healthcare professionals: a central factor in patients outcome. J Nurs Care 1:1. 